\title{
What contributes to abuse in health care? A grounded theory of female patients' stories
}

A. Jelmer Brüggemann and Katarina Swahnberg

\section{Linköping University Post Print}

\section{Tweet}

N.B.: When citing this work, cite the original article.

Original Publication:

A. Jelmer Brüggemann and Katarina Swahnberg, What contributes to abuse in health care? A grounded theory of female patients' stories, 2013, International Journal of Nursing Studies, (50), 3, 404-412.

http://dx.doi.org/10.1016/j.ijnurstu.2012.10.003

Copyright: Elsevier

http://www.elsevier.com/

Postprint available at: Linköping University Electronic Press

http://urn.kb.se/resolve?urn=urn:nbn:se:liu:diva-90196 


\title{
What Contributes to Abuse in Health Care? A Grounded Theory of Female Patients' Stories
}

\author{
Jelmer Brüggeman \\ Katarina Swahnberg
}

Gender and Medicine, Faculty of Health Sciences, Linköping University

\begin{abstract}
Background. In Sweden, 20\% of female patients have reported lifetime experiences of abuse in any health care setting. Corresponding prevalence among male patients is estimated to be $8 \%$. Many patients report that they currently suffer from these experiences. Few empirical studies have been conducted to understand what contributes to the occurrence of abuse in health care.
\end{abstract}

Objectives. To understand what factors contribute to female patients' experiences of abuse in health care.

Design. Constructivist grounded theory approach.

Settings. Women's clinic at a county hospital in the south of Sweden.

Participants. Twelve female patients who all had reported experiences of abuse in health care in an earlier questionnaire study.

Methods. In-depth interviews.

Results. The analysis resulted in the core category, the patient loses power struggles, building on four categories: the patient's vulnerability, the patient's competence, staff's use of domination techniques, and structural limitations. Participants described how their sensitivity and dependency could make them vulnerable to staff's domination techniques. The 
participants' claim for power and the protection of their autonomy, through their competence as patients, could catalyze power struggles.

Conclusions. Central to the participants' stories was that their experiences of abuse in health care were preceded by lost power struggles, mainly through staff's use of domination techniques. For staff it could be important to become aware of the existence and consequences of such domination techniques. The results indicate a need for a clinical climate in which patients are allowed to use their competence.

\section{Key words}

grounded theory; patient abuse; power; professional misconduct; qualitative research; quality of health care; Sweden

\section{What is already known about the topic?}

- Abuse in health care can lead to immediate and long term suffering in patients

- Previous research has shown high prevalence numbers of abuse in health care but little is known about what contributes to these events

\section{What this paper adds}

- The researchers found that female patients experience abuse in health care as a consequence of lost power struggles

- These power struggles stand for the clash between patients' vulnerability and competence and staff's use of domination techniques 


\section{Introduction}

It has been well-documented that female and male patients can experience suffering from encounters in health care, which is not related to their disease and even despite a medically correct treatment (Brüggemann et al., 2012a; Coyle, 1999; Levinson and Shojania, 2011; Swahnberg et al., 2009a; Swahnberg et al., 2007a; Söderberg et al., 2011). These incidents do not only imply immediate and long-term suffering, but they can also affect a patient's confidence in the health care system (Swahnberg et al., 2009b). A study among long-term sick-listed patients showed that health care encounters devoid of respect can impair their ability to return to work (Lynöe et al., 2011), pointing at far reaching consequences of untoward health care encounters. Harmful encounters or those devoid of care, as seen from patients' perspectives, have been labeled abuse in health care (Brüggemann et al., 2012a).

Female patients have described their experiences of abuse in health care as feelings of "being nullified" in qualitative interviews (Swahnberg et al., 2007b). Being nullified included aspects of feeling powerless and ignored, feelings that male patients also expressed.

However, instead of being nullified, male patients felt "mentally pinioned", as they could not act in accordance with their own convictions (Swahnberg et al., 2009b). In quantitative studies, abuse in health care was operationalized by three questions, displayed in table 1. Using this operationalization, the prevalence of abuse in health care has been extensively studied in the Nordic countries, where between 13 and 28 percent of gynecology patients $(\mathrm{n}=3641)$ reported some kind of abuse in health care (Swahnberg et al., 2007a). Prevalence in Swedish male patients was about 8 percent (Swahnberg et al., 2009a). 
*** Table 1 near here $* * *$

A theoretical framework has been developed to understand why abuse in health care occurs regardless of staff trying to provide the best care possible. The starting point is Galtung's theory of violence, which distinguishes between direct violence (face-to-face events), structural violence (processes), and cultural violence (invariants embedded in culture; Galtung, 1990). Galtung depicts these three types in a "violence triangle", emphasizing their interrelatedness. Placing cultural violence at the bottom of the triangle invokes an image of cultural violence that legitimizes and feeds both structural and direct violence. For example, in a case study it was hypothesized that staff can structurally disempower patients by the use of their knowledge, status, or a medical language, thereby making it difficult for patients to speak up (Wijma et al., 2007). This was later supported by a quantitative study, which showed that a majority of female patients kept silent to the health care system after experiencing abusive or wrongful transgressions of ethical principles by staff (Brüggemann et al., 2012b). Such silence can confirm, and thereby reproduce, existing structures, legitimizing future direct events of abuse in health care (Giddens, 1984). Glover's theory of moral identity was later used to explain how such violence can develop and exist in a system that is created to help patients (Glover, 2001; Swahnberg et al., 2006). To explain how humans in certain situations can perform inhumane deeds, Glover describes several processes that can contribute to the erosion of a person's moral identity, i.e., the kind of moral human being this person wants to be. Based on this idea, it was hypothesized that staff can move from feeling guilty about abuse in health care to ignorance, legitimized by a general taboo on talking about abuse in health care (Swahnberg et al., 2006; Wijma and Swahnberg, 2009), which was later confirmed in qualitative interviews with health care staff (Swahnberg and Wijma, 2011). 
To gain further theoretical insights in the occurrence and prevention of abuse in health care it is of importance to listen to patients' stories. In the present study we therefore turned to patients and asked them what contributed to their experiences of abuse in health care, in contrast to earlier patient studies that focused on what it meant to experience abuse in health care (Swahnberg et al., 2007b; Swahnberg et al., 2009b).

\section{Method}

\section{Design}

We applied a qualitative study design following a constructivist grounded theory approach (Charmaz, 2006). This approach has a starting point in grounded theory methodology as developed by Glaser and Strauss (Glaser, 1978; Glaser and Strauss, 1967/1999). The grounded theory methodology was developed in order to offer a rigid and credible qualitative method, as a reaction to a growing dominance of positivistic quantitative research in the mid twentieth century (Charmaz, 2006). But, as Charmaz (2006) notes, in the 1990's grounded theory was deemed problematic because of its own positivistic assumptions. Constructivist grounded theory is one approach that aims to preserve the building blocks of original grounded theory, without accepting its positivistic starting point. Contrary to the original “objectivist" approach by Glaser and Strauss, the constructivist approach assumes a relativist epistemology and emphasizes a reflexive stance toward situations and participants (Charmaz, 2009). Rather than developing general theories, a constructivist approach generates situated knowledge (Haraway, 1988), constructed in a specific local and cultural setting by the participants and the researcher. Constructivist grounded theory was chosen because of its 
focus on situatedness, participants' insights and voice and non-hierarchical relationships between researcher and participant (M. Allen, 2011b).

\section{Ethics}

The study was approved by the regional ethical review board (reg. no. M116-09). We obtained active written informed consent from all participants before start of the interview. The participants were also informed that they could withdraw from the study or contact us at any time, and that all interview material was treated confidentially.

\section{Data Collection}

During 2009 and 2010 we sent the Transgressions of Ethical Principles in Health Care Questionnaire (TEP) to 890 female patients visiting a women's clinic in the south of Sweden (response rate $60 \%, \mathrm{~N}=530$ ). Inclusion criteria were: 1 . consecutive female patients coming for an outpatient appointment (first visit during study period), 2. $\geq 18$ years old, 3. speaking and understanding the Swedish language, and 4. having a known address. TEP included questions about sociodemography, health, abuse, and transgressions of ethical principles (Brüggemann et al., 2012b). The three questions that captured abuse in health care are presented in table 1.

Patients who had answered yes to any of the questions in table 1 were eligible for the present study $(\mathrm{n}=130)$. Based on the information that patients provided in TEP, we selected participants for the study according to the principles of theoretical and purposeful sampling as part of the grounded theory design (Charmaz, 2006; Glaser, 1978; Glaser and Strauss, 1967/1999). Theoretical sampling is a continuous process during the time of data collection. As data collection and data analysis were conducted parallel to each other, we had the opportunity to consecutively select participants and even adjust some of our interview 
questions, according to what appeared to be relevant to study. The processes of data collection and analysis were in constant interaction as we aimed for the categories to become theoretically saturated (Charmaz, 2006). The first author invited patients by telephone. Of those contacted, 12 patients declined and 12 accepted participation in the study. The first author conducted all the interviews between November 2010 and June 2011. The participants were aged 30 to 78 and had diverse educational levels. They also had a varying background of abuse, abuse in health care, and self-rated health. Three participants were born outside of Sweden.

After acceptance to participate, a date and time for the interview was set and the participants were asked to think of their abusive experiences in health care in preparation of the interview. Eleven interviews were conducted in a quiet conference room and one interview was conducted by telephone for logistic reasons, while the participant was at home. Before the start of the interview participants received detailed information about the study and signed the informed consent form. The in-depth interviews were conducted according to a thematic, general interview guide including the following open-ended questions:

- Can you think of a situation where you experienced abuse in health care?

- Can you tell me what the situation looked like? Why, when, where did you seek care?

- What contributed to this situation occurring? What happened between you and the staff?

- What did staff do during the incident? What did you do yourself?

- Was there any feedback from the staff to you or from you to the staff?

- What were the consequences of the incident for you, also on the long term?

- Why do you think this happened between you and the staff involved?

- Anything more you would like to share about this event?

- Can you think of another situation where you experienced abuse in health care? 
On average the interviews lasted 44 minutes (ranging between 18 and 68 minutes) and they were audio-recorded and transcribed verbatim by the first author and a secretary.

\section{Data Analysis}

We analyzed the material by using constant comparative analysis, one of the building blocks of grounded theory (Charmaz, 2006). Initially, the first author analyzed the interview transcripts using in vivo codes identifying content related to the research question, in consultation with the second author. In a next stage he applied focused coding to synthesize the data, still using in vivo codes. Later, we both developed these in a theoretical direction by sorting the codes in categories. We constantly compared codes and categories to each other in a process to adjust, refine and confirm the constructed theory. After ten interviews we achieved saturation as no new categories emerged. Two more interviews were conducted to consolidate and stabilize the categories.

\section{Reflexivity}

Constructivist grounded theory demands reflexivity from the researcher, striving toward awareness of the self, of the interaction with the participant, and of the research process, to enforce the voice of participants (M. Allen, 2011b). Several tools were used to increase our self-awareness. First, we reflected upon our position on the social hierarchy ladder with which we entered the interviews, as this could affect our relationship with the participant considering the sensitive topic (M. Allen, 2011b). Second, we wrote an extensive log book during data collection and analysis, and we reflected upon it regularly. Moreover, in two research seminars we reflected upon the influence of our own positions within the study as researchers with experience in the field of abuse in health care. 


\section{Results}

Our study resulted in four categories using constant comparative analysis: the patient's vulnerability, the patient's competence, staff's domination techniques, and structural limitations. A core category captured the relation between the categories: the patient loses power struggles.

$* * *$ Figure 1 near here $* * *$

\section{The Patient's Vulnerability}

Patients' vulnerability signalized an initial lack of power in health care encounters. Part of this vulnerability was attributed to the actual health care situation, such as the patient's physical state and position of being dependent and helpless. One woman explicitly mentioned her dependency as a contributive factor:

Because when you ask for help you are dependent. And then you are in a crisis, because one's health is rubbed, and then one is in a state of crisis in some way.

However, the patient's vulnerability was mainly attributed to the patient herself. Patients described themselves as being very sensitive, pointing at the importance or the value of that specific moment or treatment to the patient. One participant talked about a phone call she made to make an appointment for abortion:

I don't know. One is extremely sensitive when making the phone call as well, one is sensitive to how they ask the question and [silent $<3$ seconds], one is really sensitive. ... And one is sensitive perhaps to how they say certain things and one has already 
blamed oneself and is disappointed and angry at oneself for getting pregnant again and things like that.

Other factors that contributed to patients' vulnerability were personal attributes such as their personality and their age. One middle-aged woman told of being yelled at by a physician when she was younger and said, "I was young, I had a hearing disability, I was insecure". The patient's vulnerability implies an initial powerlessness, both because of situational and personal factors.

\section{Staff's Domination Techniques}

This category stands for the many different ways in which staff's behavior, most of the time unintentionally, was experienced as increased subordination by the participants. Domination techniques should not be interpreted as methods to intentionally subordinate the patient, but rather as the consequences of staff' actions as seen from the patient's perspective. These actions included not listening to the patient, not seeing the patient, silencing untoward incidents, behaving toward the patient in a contemptuous way, and not allowing the patient to question medical expertise. Not listening to the patient could take many forms, but it always encompassed elements of not taking the patient seriously or not taking notice of her opinions. This was different from not seeing the patient, where staff talked over the head of the patient; patients felt objectified or reduced to a number. One of the patients felt invisible when a junior physician needed assistance with an ultrasound examination and called in help from a senior gynecologist: 
... that person came in talking in a cell phone and did not hang up but instead examined me with the ultrasound [laughs a little], while at the same time still holding onto his cell phone ... and walked out of the room.

The silencing of untoward events concerned the lack of an explanation of why things went wrong, but also that staff did not apologize for their behavior. Silence after an abusive incident could catalyze feelings of being abused. An example of this was a woman who emphasized the lack of an apology as part of her experiences of abuse in health care.

I think it is about respect for time [silent $<3$ seconds], because I think that I told the dentist in that very situation that it is not that I cannot understand that things can happen and one can be delayed ... but if one does not get such an explanation or apology then one really wonders [silent $<3$ seconds].

The opposite of silence was contemptuous behavior by staff that, contrary to most other domination techniques, included actions (often verbal ones) that appeared to have no other aim than to degrade or harm the patient. It could also be the lack of good manners, an insensitive attitude, or a reaction to patients questioning staff's medical expertise. Patients also experienced negative reactions from staff when they pointed out errors or made requests for transfers or second opinions, based on their own competence.

\section{The Patient's Competence}

A patient's competence stands for the possession of certain knowledge as well as the claim of this knowledge. This included knowledge of the own body, the health care system, and patient rights. One participant said the following about an encounter with her GP: 
I just did not want to take [that anti-depressive] because I knew.. sensed.. and that was probably most abusive, I felt that.. I sensed it was not psychological, but it was really hard to convey this ... in some way, or to make myself convincing that it was not psychological. I know my body so well, so to speak.

Many patients expressed that they knew their rights; some of them also worked in health care or had close family who did so, which they felt gave them extra knowledge. The patients also emphasized that this knowledge motivated or even forced them to speak up, and stand up for their beliefs.

No, but she [a midwife], I do not know if I made any demands on her or so, that she thought I was a very troublesome patient, I do not know. Because I do not think I am that troublesome as a patient, no more than that I believe I have the right to speak up when I think something is wrong.

Instead of being a protective factor, this competence was something that seemed to expose the patients to abuse in health care.

\section{Structural Limitations}

Structural limitations point at limitations on acting in a certain way and could hence affect both patients and staff. These limitations can lead directly to patients experiencing abuse in health care; e.g., a patient experienced abuse in health care when she, because of budget restraints, was forced to stay in a youth hostel at some distance from the hospital for two 
months, for radiation to treat her cancer. Another woman also experienced consequences of a lack of resources after heavy bleedings during a surgery.

And [the midwife] just pulled up her shoulders and said, well luckily we were there, now you can go home. One, really, one cannot even [laughs] stay and receive care. ... And the poor guy who drove me home was a sort of ambulance service ... because I could not drive myself. He got to support me, I could not get in the hou-, I could not stand on my legs. I think it is horrible.

The participants mainly acknowledged that structural limitations affect staff's behavior, for example how budget cuts force staff to send patients home early after an operation, or staff may have little time to engage with them. Other effects of structural limitations were that health care routines were organized in a way that made the patient feel totally powerless, without any specific abusive behavior by individual members of staff.

And what was abusive was first that they did not listen to me from the beginning, but then the most abusive was that, every time I came there was a new midwife [...]. And every time they had to go and get another doctor who made another judgment, because they have no continuity there, and then it was really abusive to lie there once a week and show yourself the way you do at a women's clinic.

... And to go through these examinations and different people each and every time ... that was terrible. 


\section{Core Category: The Patient Loses Power Struggles}

The core category represents the clash between the four categories, which ultimately ends up in experiences of abuse in health care (Figure 1).

*** Figure 1 near here $* * *$

The loss of a power struggle can be illustrated by the story of a participant who suffered from painful neurological problems without a clear diagnosis in the mid-eighties. One night during her time at the ward she felt sick and threw up all over her clothes. As she felt too weak to change clothes herself she called an auxiliary nurse for help. The nurse took a quick look and told the patient that this could wait until morning, and folded the shirt to cover the vomit. The patient felt sad, powerless and not listened to. In a later stage she chose to confront a team of physicians with a request to be moved to a university hospital. She knew this transfer would be possible as she herself had worked at the local hospital. During that confrontation the physicians laughed scornfully at her request, wondering what she thought the other hospital could do for her that they could not do here. The patient experienced that the physicians felt insulted as she was making demands, and their reactions made her feel "small like a mosquito".

The participants entered health care being vulnerable, dependent on their subordinated position, their sensitivity, and in some cases also on personal attributes such as their personality or age. This vulnerability, illustrated by the participant's helplessness in the example above, contributed strongly to why these patients had experienced abuse in health care by staff's actions. Many of staff's actions described by patients were a type of domination technique, which confirmed and enlarged existing power differences between patients and staff. These techniques included actions such as not allowing the patient to 
question medical expertise or not seeing the patient. In many cases there was probably no intention to harm the patient; it was rather an unforeseen consequence of routine behavior. The core category does not only stand for this initial struggle between the patients and staff; it is especially visible when patients solicit their own competency. When patients make a stronger claim for power by invoking their knowledge and standing up for their rights and choices, this power struggle is intensified. In turn, this claim for power could catalyze staff's use of domination techniques, resulting in the patient's loss of the struggle as illustrated in the example above. Thus there are different 'routes' from the categories down to the core category, but nearly all pass staff's domination techniques. In a last route, patients feel limited and abused by structures. Different from domination techniques, structural limitations can lead to a loss of power struggles without the involvement of individual members of staff. These structural limitations can also affect staff's domination techniques, because it functions as power inertia, maintaining power differences between patients and staff. 


\section{Discussion}

Our main research aim was to understand what factors contributed to female patients' experiences of abuse in health care. The variation in our material, based on interviews with twelve female patients, was best captured by the core category the patient loses power struggles. This core category is the result of the interaction and the clash between the four categories: the patient's vulnerability, the patient's competence, structural limitations, and staff's domination techniques. We believe this theory explains most variations in our material, but that does not mean that every patient who wanders through the model will end up feeling abused; the participants we included all had experienced abuse in health care. Not all patients who experience a lost power struggle need to feel abused by it. Another limitation of our theory is that it does not explain what happens if patients win power struggles. In these cases it could be that such a won struggle leads to a more equal relationship between patient and staff, leveling out initial power differences. In worse cases it could lead to staff abuse by patients, but these stories were not part of the current study. An important remark considering patients' competence is that this may or may not stem from "correct" information or knowledge; patients may have misinterpreted some of their rights or the available options. In the construction of our theory this was not important because we focused on capturing the selected patients' stories. The examples of the patients making claims in the current study, however, showed that they were not mainly abused by not receiving a certain treatment but rather by staff's reactions to these claims.

Our study confirms earlier findings that there exist power imbalances within the nurse-patient relationship. Henderson (2003) identifies three factors which strongly contribute to this power imbalance. First, nurses' belief that they "know best". Second, the view that patients lack medical knowledge, which can be reason not to include patients in 
decision-making processes. Third, nurses' perceived need to stay in control and hold on to the power they possess. The fact that a power imbalance exists between the nurse and the patient has also been shown by Johnson and Webb (1995), who found that the nurse-patient relationship often can be seen as a struggle, where patients are forced to fit predefined nursing goals. This struggle was also expressed by Swedish patients when asked about their perceptions of self-determination, where they felt their own will collided with that of staff (Nordgren and Fridlund, 2001). Our study is the first to show a connection between losing power struggles and feeling abused in health care.

The concept of power is central to the understanding of our core category. A main distinction can be made between power-to and power-over (Hawks, 1991). Within most feminist studies focus has been on the latter, where emphasis lies on the relationship between human beings (A. Allen, 2011a), in contrast to the former which focuses on human beings' capacities and abilities (Hawks, 1991). Our core category seems to be best understood in terms of unjust power-over relationships, or domination (A. Allen, 2011a). Within this feminist tradition, the Norwegian social psychologist Berit Ås applied the concept of domination techniques to understand how women are oppressed in society by men and a masculine hegemony (Ås, 1981). She described five such techniques: making invisible, ridiculing, withholding of information, double punishment, and heaping blame and putting to shame. Ås denies that these techniques always need to be intentional and of a manipulative character; instead they can be unintentional and invisible, embedded in routines and learned behavior. Three of our domination techniques are also found in Ås’ theory: making invisible, ridiculing, and double punishment. Ås' technique of making invisible would include not being seen and not being listened to, which, according to her, could lead to the erosion of a person's identity. This consequence has also been seen in patients who feel dissatisfied, describing their experiences as a 'personal identity loss' (Coyle, 1999). Ridiculing can be 
equaled to what was labeled contemptuous behavior in the present study. We can also find the technique double punishment in our results, although not as a single code. Ås describes this technique as "damn you if you do and damn you if you don't" and we can find this in our category the patient's competence. Instead of being protected by their expert knowledge, the participants lost power struggles. These patients seemed to be in a position where they could either choose to subordinate to health care staff, thereby from their perspective unjustly sacrificing parts of their autonomy, or choose to use their knowledge and rights to improve their treatment, thereby risking experiencing abuse in health care.

As domination techniques are to be understood as actions mainly embedded in routines, it is hard to separate them from structural limitations. In this study, we saw a difference between these categories, because staff's domination techniques involved interactions with individual members of staff, while structural limitations consisted of procedures or regulations. However, these procedures and regulations can affect the use of domination techniques. General working routines at a clinic that make it impossible for patients to visit the same nurse at multiple occasions could increase the risk for staff to make the patient feel invisible. Participants seldom made this connection in their descriptions of the events and focused mainly on their interactions with staff. This is not surprising, because patients often do not have the organizational insights required to see how staff's behavior is affected by such constraints. However, even when participants did make this connection, they still saw many opportunities for staff how they could have prevented the abusive situation. Such "simple" actions could include presenting oneself, providing clear information, and apologizing for a situation irrespective of what or who caused the situation. Counter strategies and validation techniques to fight domination techniques are further developed under 'Clinical Implications'. 
Connecting the theoretical insights from the present study to our earlier theoretical framework gives a deeper understanding of the occurrence of abuse in health care. It is beyond the scope of the current article to fully develop this framework, but we will sketch the larger picture (Figure 2). Domination techniques represent how patients experienced staff's direct behavior toward them when they experienced abuse in health care. These techniques are hence a form of, what Galtung labels 'direct violence' or face-to-face incidents (Galtung, 1990). These direct events are culturally embedded and affected by 'violent' structures, or the structural limitations that we found in the current study, and cannot be separated from this context. Glover's theory may to some degree explain staff's unintended use of domination techniques. An erosion of moral identity, which is at the heart of Glover's theory (Glover, 2001), might be a reason why domination techniques can prevail and go unnoticed by staff. Moral identity is a moral resource that is needed for moral behavior (Glover, 2001; Rest, 1994), and an erosion of identity might lead to different behavioral paths. If, at the same time, patients remain silent to health care staff after the abuse (Brüggemann et al., 2012b), it is very hard for staff to become aware of any domination techniques.

*** Figure 2 near here $* * *$

\section{Trustworthiness}

The quality of constructivist qualitative research can be judged according to its trustworthiness, as opposed to the positivist concepts of validity and reliability (Bowen, 2008; Denzin, 1994). Trustworthiness consists of four elements: credibility and transferability (comparable to internal and external validity respectively), as well as dependability and confirmability (comparable to reliability and objectivity; Lincoln and Guba, 1985). Our strategies to increase the credibility of the study were transparency of method, investigator 
triangulation, and peer review by other qualitative researchers as well as clinicians. We chose not to perform member checking, i.e., having the theory confirmed by participants, because we agree with Morse et al. that it risks invalidating a theory because participants might demand a theory closer to their descriptions (Morse et al., 2002). It is important to discuss our material and sample, so that others can fairly judge the transferability of our results. Our aim was not to generalize, but to include an adequate sample, which includes participants who have specific knowledge on the topic, can reflect upon what happened and have the time and will to participate (Morse, 1994). Purposeful and theoretical sampling is not about generalizing results or representing a population, rather we applied it to capture a wide spectrum of aspects of the phenomenon and to help in understanding where to find descriptions of these aspects (Charmaz, 2006). One aspect that we did not study was how patients' autonomy affected their experiences of abuse in health care. Our sample was selected from a female gynecology patient population, and did not include patients with limited autonomy such as patients with severe mental disabilities or children. We also know that gender is relevant for patients' experiences of abuse in health care, as men and women told different stories about their experiences (Swahnberg et al., 2007b; Swahnberg et al., 2009b). Hence we cannot assume that our theory captures male patients' stories as well and research on this topic is desired. Although some of our patients were not born in Sweden, all of the participants' experiences should be seen within a Swedish context; abuse in health care could have different contributive factors in other cultural settings. All participants were Swedish speaking, which limits the transferability of the results because it is not known to what extent and how patients who do not understand Swedish experience abuse in health care. Dependability was increased parallel with the credibility of the study, by means of transparency of method, investigator triangulation, and peer review. Finally, considering confirmability, our rich use of examples and citations gives insight in how codes and 
categories are supported by data. Also, we emphasized reflexivity in the research process, by constantly analyzing our own position in data collection and analysis. Our previous studies in the field and theoretical ideas about abuse in health care increased our understanding of the participants' stories and their dependency in the health care encounters. Some of these preconceived ideas may have impacted the construction of the categories, which is most visible in the category of structural limitations. Our previous use of Galtung's theory and his concept of structural violence may have increased our interest in structural components in the participants' stories. Noticing this tendency after five interviews, as was written down in our logbook, enabled us to go back and forth between the data and our previous ideas in a rather early stage of the study.

\section{Cinical Implications}

For health care professionals it is important to become aware of the potential consequences of domination techniques, and patients could be invited and stimulated to effectively counter these techniques. In general, people can apply counter strategies such as taking up space and demanding respect, questioning the one that ridicules, or communicating their priorities (Amnéus et al., 2004). The problem with these counter strategies, however, is that they are hard to apply by patients in a vulnerable position. On top of that, in the current study we saw that participants' competence, of which counter strategies can be part, could lead to further abuse in health care. We believe that it cannot be asked from patients to counter staff's behavior, but patients can still be empowered to do so, focusing on "power to" rather than "power over". This implies that health care professionals change roles as well (Aujoulat et al., 2007), creating a climate where patients are invited to counter staff's behavior. Validation techniques are the opposite of domination techniques and can be tools for staff to change their relationships with patients. A first validation technique is to make other persons feel 
visible, by listening and giving constructive advice. A second is to encounter the other in a serious way and with respect, and by giving the other the opportunity to participate in the

encounter. A third is to assume that whatever the patient does, she is trying to do the best she can. This way, the patient is rewarded, rather than blamed, for her choice of, e.g., soliciting her competence. Applying validation techniques as staff can be an alternative way of dealing with power struggles within the structural limitations of the health care encounter. However, it may also be important for health care staff, including nurses, to make these structural limitations visible to themselves and their clinic. This asks for a clinical environment in which nurses are motivated to "speak up" about their concerns.

\section{Conclusion}

High prevalence of abuse in health care has been reported but little is known about what contributes to these events. In this qualitative study we turned to female patients and asked them what contributed to their experiences of abuse in health care. The participants' stories of these experiences were best described by the core category 'the patient loses power struggles'. These patients' sensitivity and dependency could make them vulnerable to staff's dominations techniques. Power struggles could be catalyzed by the patients' claims for power, when they solicited their competence as patients. These findings suggest the importance of an increased awareness and understanding of the use of domination techniques and how staff can avoid these techniques. Future studies could concentrate on male patients' and staff's narratives about what contributes to patients' experiences of abuse in health care. 


\section{References}

Allen, A., 2011a. Feminist perspectives on power. In E. Zalta (Ed.), The Stanford Encyclopedia of Philosophy (Spring 2011 Edition). Retrieved from http://plato.stanford.edu/archives/spr2011/entries/feminist-power/ on 1 February 2012

Allen, M., 2011b. Violence and voice: Using a feminist constructivist grounded theory to explore women's resistance to abuse. Qualitative Research, 11 (1), 23-45.

Amnéus, D., Eile, D., Flock, U., Rosell Steuer, P., Testad, G., 2004. Validation techniques and counter strategies: Methods for dealing with power structures and changing social climates. Stockholm University, Stockholm

Aujoulat, I., d'Hoore, W., Deccache, A., 2007. Patient empowerment in theory and practice: polysemy or cacophony? Patient Education and Counseling, 66 (1), 13-20.

Bowen, G.A., 2008. Naturalistic inquiry and the saturation concept: a research note. Qualitative Research, 8 (1), 137-152.

Brüggemann, A.J., Wijma, B., Swahnberg, K., 2012a. Abuse in health care: A concept analysis. Scandinavian Journal of Caring Sciences, 26 (1), 123-132.

Brüggemann, A.J., Wijma, B., Swahnberg, K., 2012b. Patients' silence following healthcare staff's ethical transgressions. Nursing Ethics, Published online 30 April 2012, doi $10.1177 / 0969733011423294$.

Charmaz, K., 2006. Constructing grounded theory: A practical guide through qualitative analysis. SAGE, Thousand Oaks.

Charmaz, K., 2009. Shifting the grounds: constructivist grounded theory methods. In J.M. Morse, P.N. Stern, J.M. Corbin, B. Bowers, K. Charmaz, A.E. Clark (Eds.), Developing grounded theory: The second generation. Left Coast Press, Walnut Creek, pp. 127-154. 
Coyle, J., 1999. Exploring the meaning of 'dissatisfaction' with health care: The importance of 'personal identity threat'. Sociology of Health \& Illness, 21 (1), 95-123.

Denzin, N.K., 1994. The art and politics of interpretation. In N.K. Denzin, Y.S. Lincoln (Eds.), Handbook of qualitative research. Sage, Thousand Oaks, pp. 500-515.

Galtung, J., 1990. Cultural Violence. Journal of Peace Research, 27 (3), 291-305.

Giddens, A., 1984. The constitution of society: Outline of the theory of structuration. University of California press, Berkeley, CA.

Glaser, B., 1978. Theoretical sensitivity. Sociology Press, Mill Valley, CA.

Glaser, B., Strauss, A., 1967/1999. The discovery of grounded theory: Strategies for qualitative research. Aldine, Chicago.

Glover, J., 2001. Humanity. A moral history of the twentieth century. Pimlico, London.

Haraway, D., 1988. Situated knowledges: The science question in feminism and the privilege of partial perspective. Feminist Studies, 14 (3), 575-599.

Hawks, J.H., 1991. Power: a concept analysis. Journal of Advanced Nursing, 16 (6), 754-762.

Henderson, S., 2003. Power imbalance between nurses and patients: a potential inhibitor of partnership in care. Journal of Clinical Nursing, 12 (4), 501-508.

Johnson, M., Webb, C., 1995. The power of social judgement: Struggle and negotiation in the nursing process. Nurse Education Today, 15 (2), 83-89.

Levinson, W., Shojania, K.G., 2011. Bad experiences in the hospital: the stories keep coming. BMJ Quality \& Safety, 20 (11), 911-913.

Lincoln, Y.S., Guba, E.G., 1985. Naturalistic inquiry. Sage, Beverly Hills, CA.

Lynöe, N., Wessel, M., Olsson, D., Alexanderson, K., Helgesson, G., 2011. Respectful encounters and return to work: empirical study of long-term sick-listed patients' experiences of Swedish healthcare. BMJ open, 1 (2). 
Morse, J.M., 1994. Designing funded qualitative research. In N.K. Denzin, Y.S. Lincoln (Eds.), Handbook of qualitative research. SAGE, Thousand Oaks.

Morse, J.M., Barrett, M., Mayan, M., Olson, K., Spiers, J., 2002. Verification strategies for establishing reliability and validity in qualitative research. International Journal of Qualitative Methods, 1 (2), 13-22.

Nordgren, S., Fridlund, B., 2001. Patients' perceptions of self-determination as expressed in the context of care. Journal of Advanced Nursing, 35 (1), 117-125.

Rest, J.R., 1994. Background: Theory and research. In J. Rest, D. Narváez (Eds.), Moral development in the professions: Psychology and applied ethics. Lawrence Erlbaum Associates, New Jersey, pp. 1-26.

Swahnberg, K., Hearn, J., Wijma, B., 2009a. Prevalence of perceived experiences of emotional, physical, sexual, and health care abuse in a Swedish male patient sample. Violence and Victims, 24 (2), 265-279.

Swahnberg, K., Schei, B., Hilden, M., Halmesmaki, E., Sidenius, K., Steingrimsdottir, T., et al., 2007a. Patients' experiences of abuse in health care: a Nordic study on prevalence and associated factors in gynecological patients. Acta Obstetricia et Gynecologica Scandinavica, 86 (3), 349-356.

Swahnberg, K., Thapar-Bjorkert, S., Bertero, C., 2007b. Nullified: women's perceptions of being abused in health care. Journal of Psychosomatic Obstetrics and Gynecology, 28 (3), 161-167.

Swahnberg, K., Wijma, B., 2003. The NorVold Abuse Questionnaire (NorAQ): validation of new measures of emotional, physical, and sexual abuse, and abuse in the health care system among women. European Journal of Public Health, 13 (4), 361-366. 
Swahnberg, K., Wijma, B., 2011. Staff's awareness of abuse in health care varies according to situation and possibilities to act. Journal of Psychosomatic Obstetrics \& Gynecology, $32(2), 65-71$.

Swahnberg, K., Wijma, B., Hearn, J., Thapar-Björkert, S., Berterö, C., 2009b. Mentally pinioned: men's perceptions of being abused in health care. International Journal of Men's Health, 8 (1), 60-71.

Swahnberg, K., Wijma, B., Liss, P.E., 2006. Female patients report on health care staff's disobedience of ethical principles. Acta Obstetricia et Gynecologica Scandinavica, 85 (7), 830-836.

Söderberg, S., Olsson, M., Skär, L., 2011. A hidden kind of suffering: female patient's complaints to Patient's Advisory Committee. Scandinavian Journal of Caring Sciences, 26 (1), 144-150.

Wijma, B., Swahnberg, K., 2009. Stories never told - How concealment nurtures violence. In C. Åsberg, K. Harrison, B. Pernrud, M. Gustavson (Eds.), Gender delight : science, knowledge, culture, and writing ... : for Nina Lykke Tema Genus, Linköping, pp. 217228.

Wijma, B., Thapar-Bjorkert, S., Hammarstrom, N.C., Swahnberg, K., 2007. Cycles of abuse nurtured by concealment: a clinical report. Journal of Psychosomatic Obstetrics and Gynecology, 28 (3), 155-160.

Ås, B., 1981. Kvinner i alle land...: håndbok i frigjøring (Women of the world: a liberation handbook). Aschehoug, Oslo. 


\begin{tabular}{|l|l|}
\hline Mild abuse & $\begin{array}{l}\text { Have you ever felt offended or grossly degraded while visiting health care services, felt that } \\
\text { someone exercised blackmail against you or did not show respect for your opinion - in such a } \\
\text { way that you were later disturbed by or suffered from the experience? }\end{array}$ \\
\hline Moder ate abuse & $\begin{array}{l}\text { Have you ever experienced that a "normal" event, while visiting health care services suddenly } \\
\text { became a really terrible and insulting experience, without you fully knowing how this could } \\
\text { happen? }\end{array}$ \\
\hline Severe abuse & $\begin{array}{l}\text { Have you ever experienced anybody in health service purposely - as you understood - hurting } \\
\text { you physically or mentally, grossly violating you or using your body and your subordinated } \\
\text { position to your disadvantage for his/her own purpose? }\end{array}$ \\
\hline $\begin{array}{l}\text { Answer alternatives (the same for all questions): } 1 \text { = No, 2 = Yes, as a child (<18 years), 3 } \\
=\text { Yes, as an adult ( } \geq 18 \text { years), } 4=\text { Yes, as a child and as an adult. }\end{array}$ \\
\hline
\end{tabular}

Table 1: Validated questions about abuse in health care from the NorVold Abuse Questionnaire (Swahnberg and W ijma, 2003) 
Figure 1: W hat contributes to patients' experiences of abuse in health care? Categories and core category (number of interviews within parentheses)

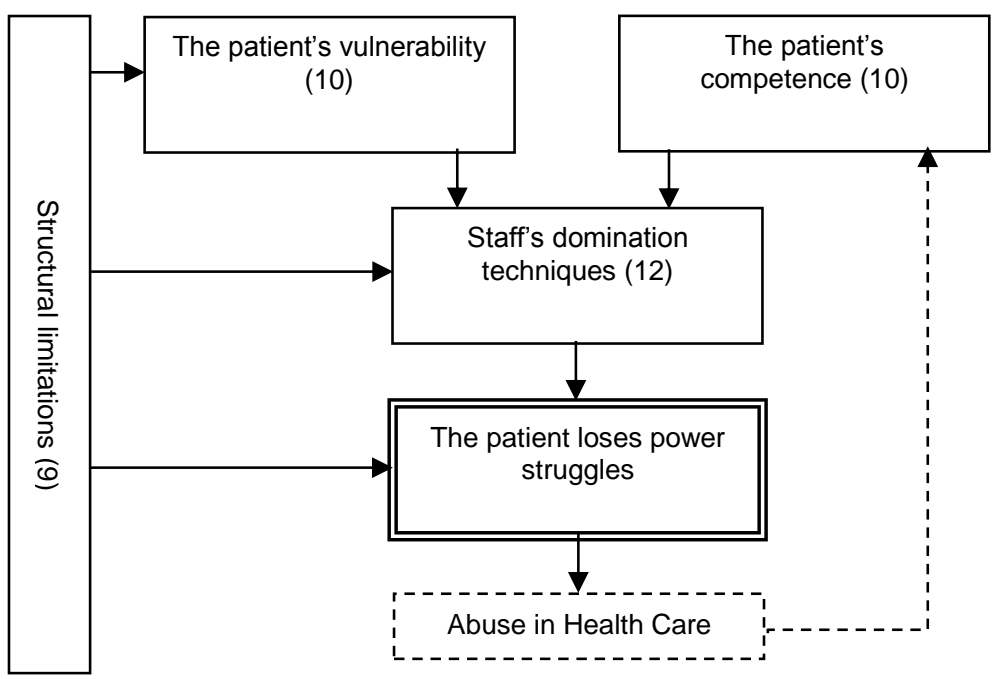


Figure 2: Connecting the results from the present study with our earlier theoretical framework

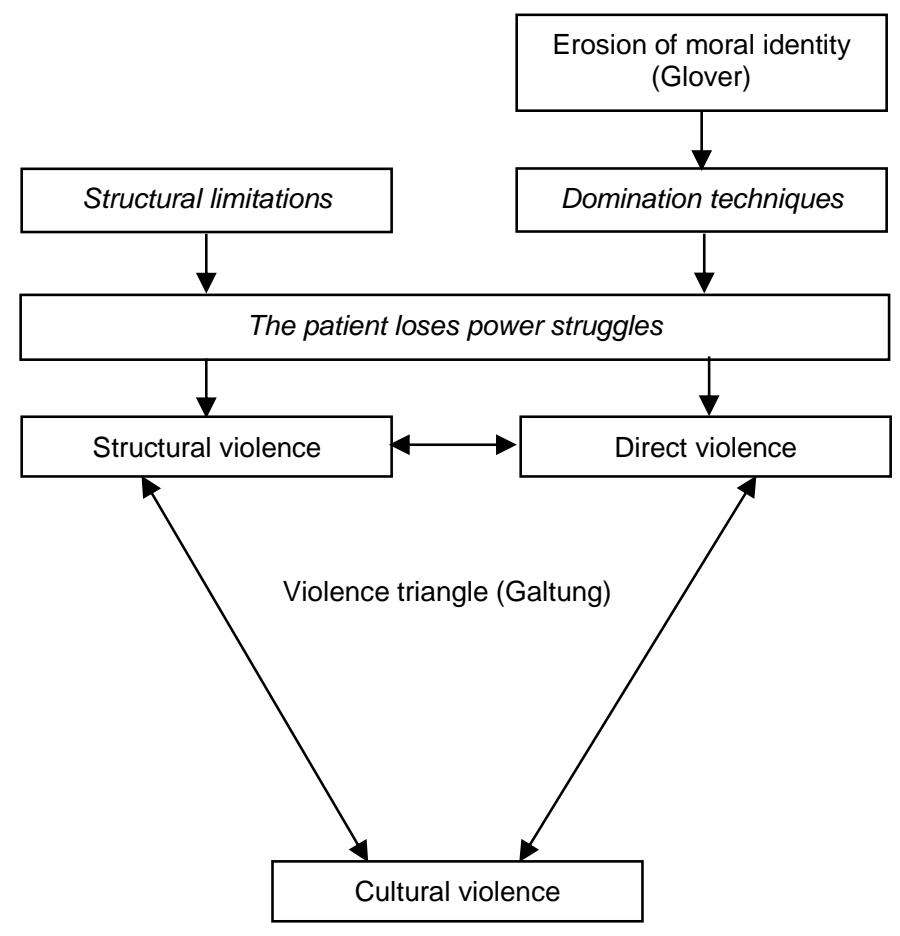

